commented. The methods by which the artist achieved such wonderfully spirited and life-like results were simple indeed. Coloured earth, pounded stones, charcoal, blood, and bird-fat constituted his pigments. A flat stone was his primitive palette. His brushes were perhaps made of the coarse hair of the male wildebeeste or buffalo. Elsewhere he scratched on the walls of his rock-shelter with a stone a little harder than the surface to be adorned. Much interest is obviously shown in the details. Obscenity, as such, is rare. By way of illustration of the technique of these drawings, a copy of a Bushman battle picture from the Natal side of the Drakensberg Range, near Bushman's Pass, and an unpublished drawing by a member of the Kamilaroi tribe of eastern Australia were exhibited, and compared to the disadvantage of the latter in strength, vividness, and accuracy of portrayal. Finally, the object and meaning of the drawings were touched upon, but not discussed, by the author, possibly because too little is known as yet; perhaps too little ever will be known to give rise to more than conjecture. It may be observed, however, that the late Mr. G. W. Stow, the author of a book recently published on the natives of South Africa, formed a large collection of copies of Bushman drawings. These were examined by the president and several members of the section after the meeting was over, and a strong desire was expressed that they should be published. If this could be done, a careful collation might result in some conclusions as to the motives which prompted and the circumstances which developed these remarkable exhibitions of artistic power by a people usually accounted so low in the scale of humanity-conclusions which might, moreover, throw unexpected light on the similar memorials left by the palæolithic people of central France.

A descriptive summary of recent discoveries of stone implements in South Africa was presented by Mr. J. P. Johnson.

Mr. A. E. Mabille read a paper on the Basuto. As a grandson of the famous missionary Casalis, who had lived (except for a few years when he was completing his education at Paris) his whole life in touch with the people, the author was specially fitted to deal with the subject and the paper was valuable for the statistics it contained and the picture it offered of the present condition and customs of the Basuto under the British protectorate. In the discussion which followed some exception was taken to the use of the word Modimo for God, but the author defended its use on the ground that it was the word long ago adopted by the missionaries, and, whether rightly or wrongly adopted at that time, its use was now fully understood and accepted among the Basuto themselves.

On Wednesday, August 30 , Prof. von Luschan read a paper on the racial affinities of the Hottentots, in which he contended, mainly on the evidence of the Hottentot language, that the Hottentot were a Hamitic people which had come into contact with the Bushmen and absorbed Bushman characteristics. Apart from a few roots and clicks, he declared the Hottentot language to be strictly Hamitic. On the physical side, the loss of their original high stature and the acquisition of steatopygia and of the spiral curled hair of the Bushman have been the penalties of intermarriage with the pigmy people.

Mr. Randall MacIver exhibited and described a number of lantern slides of the Rhodesian ruins. His report on his recent examination of the ruins was read in greater detail at an evening meeting at Bulawayo. It may here be said, however, that he has with some probability established by his researches the native origin of the ruins, and shown that most of them are of no great antiquity, in no case going back to mote than 600 or 700 years. They are essentially Bantu kraals in stone. Great Zimbabwe he identified with the capital of Monomotapa, as described by the earlier Portuguese travellers. All the problems connected with the ruins are not yet solved. We are still ignorant what gave the artistic and military impulses to the erection of these structures, against what enemy they were planned, and what led to their ruin and abandonment. These matters can only be determined, if at all, by accurate scientific exploration, and not by mere speculation like much of that which has been hitherto wasted upon these mysterious remains.

NO. I $88 \mathrm{I}$, VOL. 73 ]
Not the least important day in this section was Friday, September $x$. Besides papers by the well known missionary $M$. Junod on the Thonga tribe (illustrated by an interesting exhibition of native music, both vocal and instrumental), and by Mr. J. W. Shepstone, C.M.G., giving a general sketch of the native tribes, two striking communications were read, the one by the Rev. E. Gottschling on the Bawenda, and the other by the Rev. W. C. Willoughby on the totemism of the Bechuana. Mr. Gottschling's paper was partly historical, partly descriptive, and gave a number of particulars hitherto unpublished relating to the Bawenda, a tribe of Bantu in the north-east of the Transvaal, and their customs and beliefs. Some of the details were of quite extraordinary interest. Mr. Willoughby's paper was a discussion of a number of points connected with the totemic practices and of the relation to them of various ceremonies not usually regarded as totemic in origin, in which oxen and certain vegetables play an important part. The writer's conclusions were open to much debate, for which little time was found. The paper, however, as a whole was so suggestive, directing attention to aspects of the Bantu religious ceremonies other than those from which they are usually regarded, that it will be a great pity if this paper, as well as that of Mr. Gottschling, be not published in some form accessible to anthropologists.

The business of the section was wound up with graceful words of thanks by the president to the local committee, and in particular to Mr. A. von Dessauer, the local sectional secretary, to whose energy, forethought, and organising ability the success of the Johannesburg meeting was so largely due.

\section{THE SOLAR OBSERVATORY ON MOUNT WILSON, CALIFORNIA.}

IN a report entitled "A Study of the Conditions for Solar Research at Mt. Wilson, California," an outline was given of the circumstances that have resulted in the establishment of a solar observatory on Mount Wilson by the Carnegie Institution of Washington. At the recent annual meeting of the board of trustees, a grant of 150,000 dollars was authorised, for use during 1905. It is expected that the first equipment will cost about twice this sum, and that important additions will result in the future from the operation of a large and well appointed instrument and optical shop.

In April, 1904, a grant of 10,000 dollars was made by the executive committee of the Carnegie Institution for the purpose of bringing the Snow telescope to Mount Wilson from the Yerkes Observatory. An expedition for solar research was accordingly organised under the joint auspices of the University of Chicago and the Carnegie Institution, with the understanding that the funds granted by the Carnegie Institution would be used for the construction of piers and buildings, and for other expenses incidental to the work, while the University of Chicago would furnish the instrumental equipment and pay the salaries of some of the members of the party.

It is a fortunate circumstance that the construction and use of a great reflecting telescope, with a five-foot mirror, is in the general plan of research laid down for the Solar Observatory. In "Year Book" No. 2 (p. 49) of the Carnegie Institution may be found a report on this subject, prepared at the request of Profs. Boss and Campbell, my colleagues on the committee, and improved in many particulars as the result of their criticisms. The prime object of the Solar Observatory is to apply new instruments and methods of research in a study of the physical elements of the problem of stellar evolution. Since the sun is the only star near enough the earth to permit its phenomena to be studied in detail, special attention will be devoted to solar physics. It is hoped that the knowledge of solar phenomena thus gained will assist to explain certain stellar phenomena. Conversely, the knowledge of nebular and stellar conditions to be obtained through spectroscopic and photographic investigations with the

I Abridged from No. 2 of " Contributions from the Solar Observatory of the Carnegie Institution of Washington," by Prof. G. E. Hale, director
of the Observatory 
five-foot reflectur should throw light on the past and future condition of the sun. All the principal researches will thus be made to converge on the problem of stellar development. The name "Solar Observatory" is regarded as appropriate, since the spectroscopic study of stars and nebulæ, to be carried on in connection with the solar work, are essential elements in any attempt to determine the mode of origin, the development, and the decay of the sun as a typical star.

How, then, shall we attack in an effective manner the complex problem of stellar evolution? It goes without saying that I can offer no general answer to this question; I can only point out the three principal lines of attack which we hope to pursue at the Solar Observatory. These involve :-

(I) The more complete realisation of laboratory conditions in astrophysical research, through the employment of fixed telescopes of the coelostat type, and through the adoption of a coudé mounting for the five-foot reflector. This should permit (a) the use of mirrors or objectives of great focal length, thus providing a large image of the sun for study with spectroscopes and spectroheliographs; (b) the use of long focus grating spectroscopes, mounted in a fixed position in constant temperature laboratories, for the photography of stellar spectra requiring very long exposures; $(c)$ the use of various laboratory instruments, such as the radiometer, which cannot be employed in conjunction with moving telescopes.

(2) The development of the spectroheliograph in the various directions suggested by recent work at the Yerkes Observatory, including the photography of the entire solar disc with dark lines of hydrogen, iron, and other elements; further application of the method of photographing sections of flocculi corresponding to different levels; special studies of sunspots, \&c.; and daily routine records of calcium and hydrogen flocculi and prominences.

(3) The construction of a five-foot equatorial reflector, with coudé mounting, and its use in the photography of nebulæ, the study of stellar and nebular spectra, and the measurement of the heat radiation of the brighter stars.

It was originally intended that a prolonged series of determinations of the solar constant, extending over at least one sun-spot period, should be made an important feature of the observatory's work. The plans outlined in "Year Book" No. 2 accordingly included an equipment at Mount Wilson for this purpose, and suggested, in harmony with Dr. Langley's view, that provision be made for two additional stations, one near the summit of a high mountain, at an elevation of about 12,000 feet, the other at a much lower level on the same mountain. The principal purpose of these two stations was to measure the atmospheric absorption, in order to eliminate it from the solar constant determinations. The recent developments of Dr. Langley's researches at Washington have led Mr. Abbot, who is associated with Dr. Langley in the work, to the conclusion that entirely satisfactory results can be obtained there by the method employed. The poor atmospheric conditions with, which the Washington' observers have so successfully contended, and the disturbances arising from ground tremors in the heart of a large city, would be largely eliminated at Mount Wilson. For this reason it seems probable that results of higher precision could be obtained at this site.

In addition to the above mentioned observations, provision will be made at Mount Wilson for various laboratory investigations necessary in conjunction with solar research. In view of the importance of securing a complete record of solar phenomena when magnetic storms are in progress, NO. I 88 I, VOL. 737 suitable magnetic apparatus, recommended by Dr. L. A. Bauer, in charge of the department of terrestrial magnetism of the Carnegie Institution, will be installed at a sufficient distance from the electrical machinery.

As no description of the Snow telescope has been published, the present brief account may be prefaced by a statement regarding the construction of the teléscope.

In 1900, after Prof. Ritchey had succeeded Prof. Wadsworth as superintendent of instrument construction at the Yerkes Observatory, a cœlostat with mirror of 15 inches $(38 \mathrm{~cm}$.) aperture was made, from Prof. Ritchey's designs, for the total solar eclipse of that year. This gave such satisfactory results that the plan of constructing a large cœlostat was again taken up. Unfortunately, however, no funds were available for this purpose. In rgor, during a visit to the observatory of Prof. Cross, chairman of the Rumford committee, I showed him the details of the instrument, as worked out by Prof. Ritchey. The design called for a cœlostat of 30 inches $(76 \mathrm{~cm}$.) aperture, with second plane mirror of 24 inches $(6 \mathrm{I} \mathrm{cm}$.) aperture, the latter mounted so as to slide north-east and south-west on rails lying east of the cœlostat. The concave mirror, to which the light was reflected from the second plane mirror,

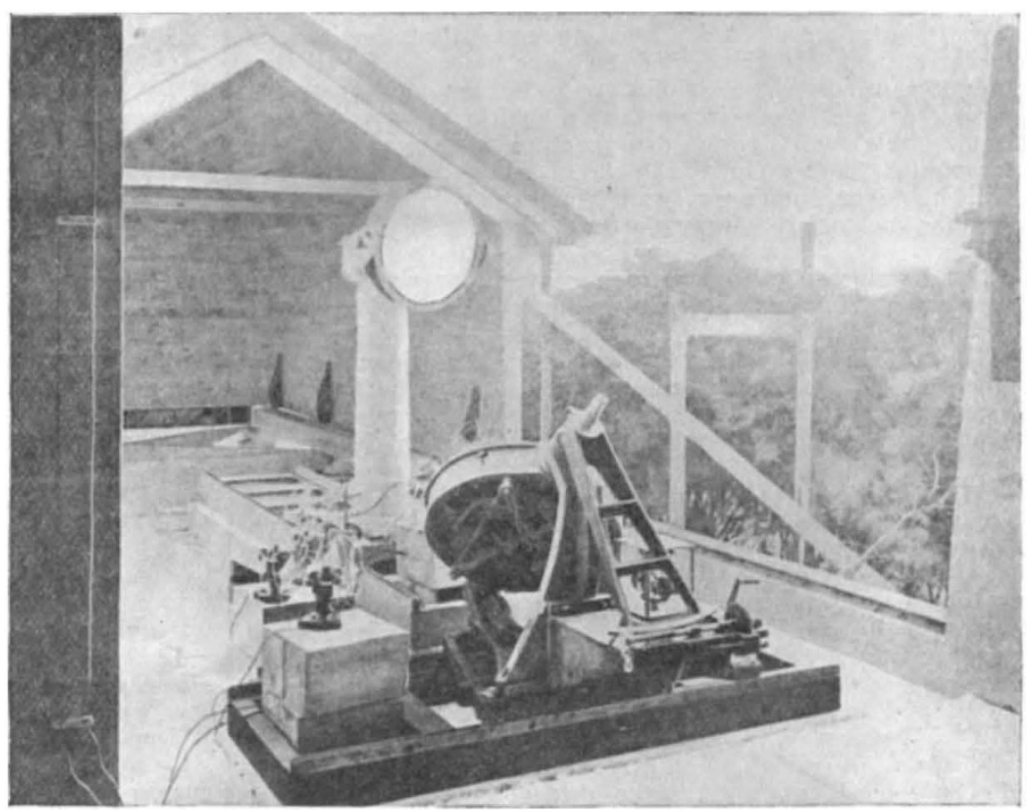

IG. r. - The Snow Telescope when mounted at the Yerkes Observatory.

had a focal length of $6 \mathbf{r}$ feet, and a second concave mirror, of 165 feet $(50.3 \mathrm{~m}$.) focal length, was also to be used.

At the kind suggestion of Prof. Cross, a grant of 500 dollars was made by the Rumford committee in aid of an investigation to be undertaken with this telescope. Subsequently, through the kindness of Prof. Pickering, chairman of the Draper committee, two other grants, of 500 dollars each, became available. With these funds, helped out by small amounts obtained from other sources, the work was begun.

A gift of I0,000 dollars from Miss Helen Snow, of Chicago, in memory of her father, the late George W. Snow, provided sufficient funds to complete the telescope and to instal it in a suitable house. The colostat was mounted on a brick pier, at a height of ${ }_{5} 5$ feet $(4.57 \mathrm{~m}$.) above the ground. In Prof. Ritchey's design of the previous instrument the rays were reflected in a northeasterly direction from the cœlostat mirror to a second plane mirror, which sent them toward the south-west to one or the other of the concave mirrors. In designing the Snow telescope, a new arrangement of the second mirror was adopted by Prof. Ritchey, at the suggestion of $\mathrm{Mr}$. C. G. Abbot. As Fig. I indicates, the light is reflected upward and to the south from the cœlostat mirror to a 
second plane mirror, mounted in a fork at the upper extremity of an iron column, on a carriage which can be moved along heavy iron rails. The position of this carriage on the rails depends upon the declination of the observed object; with a low sun the second mirror stands close to the coelostat, but with a high sun it must be moved away in order to intercept the reflected beam. The ccelostat itself may be moved east or west on its own rails, so that a low object near the meridian may not be hidden by the second mirror or its support.

With the exception of the solar and stellar spectroscopes, for which suitable gratings could not be obtained, the Snow telescope was practically completed in the autumn of 1903. On October 3 of that year it was formally presented to the University of Chicago by Miss Snow, in the presence of a number of guests.

In designing the new colostat house on Mount Wilson I was influenced by two principal considerations:-(I) The importance of placing the colostat as far as possible above the ground, which had been indicated by observations made with a telescope in a tree at elevations ranging from 20 feet to 70 feet; (2) the importance of constructing the house in such a way as to reduce to a minimum the heating and the radiation of the floor, walls, and ceiling, with the purpose of keeping the air within the house at the same temperature as the outer air.

The coelostat, and the supports for the plane mirror and the 6o-feet concave mirror, are now in place on the piers, but heavy storms have prevented the mirrors from being mounted. The concave grating stellar spectrograph is nearly ready to be set up, and work is well advanced on the smaller of the two spectroheliographs. The ultraviolet glass prisms and lenses for the stellar spectrograph have been completed by the Carl Zeiss Company, and orders have been placed for the optical parts of the 30 -feet spectroheliograph and the Littrow spectrograph. Through the courtesy of the president and trustees of the University of Chicago, the Snow telescope and some of its accessories will be used by the Solar Observatory for some time. It will subsequently be replaced by a similar telescope constructed in our own instrument shop.

\section{UNIVERSITY AND EDUCATIONAL INTELLIGENCE.}

OxForD.-The following examiners have been appointed in the science schools:-in physics, Mr. W. C. D. Whetham; in anatomy, Mr. A. H. Young; in physiology, Mr. Leonard Hill; in pathology, Dr. E. W. Ainley Walker; in forensic medicine, Dr. A. L. Ormerod; in medicine, Dr. J. R. Bradford; in surgery, Mr. H. J. Stiles; in obstetrics, Sir Arthur V. Macan; in preliminary physics, Mr. C. E. Haselfoot; in preliminary chemistry, Mr. A. Angel; in preliminary botany, Prof. J. Reynolds Green.

The Burdett-Coutts scholarship for 1905 has been awarded to Mr. James A. Douglas, Keble College.

The Junior Scientific Club held its 276 th meeting in the museum on November 8. Prof. Gotch exhibited the Gotch ophthalmic spinthariscope, and Dr. H. M. Vernon read a paper on the chemical constitution of protoplasm.

CAMBRIDGE.-The election of the well known scholar Mr. F. C. Burkitt, of Trinity College, to the Norrisian chair of divinity has a certain interest outside theological circles. It is, we believe, the first time that a layman has been elected to a chair of theology in the University of Cambridge. The Norrisian chair is open to laymen, but until this year has invariably been held by clergymen. That the heads of houses, who form the electing body, should have made this departure is perhaps a sign of the times.

Mr. C. T. R. Wilson, Sidney Sussex College, has been re-appointed demonstrator of experimental physics for a period of five years from Michaelmas, 1905.

On Monday, November 6, the following were elected to vacant fellowships at St. John's College:-Mr. J. W. H. Atkins, lecturer in English at the Victoria University, Manchester, and Mr. Frank Harton, for research in physics, I903, Allen student, 1904; D.Sc. London and NO. I 88 I VOL. 73 !
Mackinnon student of the Royal Society. Mr. Horton joinea the university as an advanced student.

IN connection with Sir Donald Currie's offer of 20,000l. to Queen's College, Belfast, on condition that a similar sum is raised by those interested in the welfare of the college, President Hamilton announced on November II that subscriptions forthcoming to that date amount to nearly $16,000 l$. The remainder of the sum must be subscribed, according to Sir Donald Currie's conditions, before Christmas.

WE learn from Science that Mr. Andrew Carnegie has offered 20,000 . to Union College, for an engineering building, on condition that the institution raises a like amount for this purpose. Mr. Carnegie has also offered to give Smith College one-half of $25,000 l$. required for a biological laboratory. It is worthy of note that the first of the initial group of seven structures that form the new Carnegie Technical Schools, in Pittsburg, Pennsylvania, has been opened with a class of 120 students, selected from more than 600 applicants.

THE Department of Agriculture and Technical Instruction for Ireland will award in July, I906, not more than ten open scholarships and ten limited scholarships to assist students of domestic economy to undertake the full course of instruction at the Irish Training School of Domestic Economy, Dublin. Scholarships will entitle the holders to free admission to the full course of training. The school is not residential, and no subsistence allowance is given. The scholarships will be awarded as the result of a competitive examination. Forms of application may be obtained from the secretary of the department after January $I$, 1906.

A Times correspondent reports that the trustees of the Witwatersrand Council of Education have decided to dispose of a sum of I $5,000 l$., raised in 1899 to provide elementary education for the Uitlander community, in the following manner. The Transvaal Technical Institute is to receive $60,000 l$. and $30,000 l$. is to be used to found a public school at Frankenwald on the lines of an English public school. The remaining $25,000 l$. will probably be divided between Jeppestown High School and Johannesburg College, but is held over until the publication of the report of the Government Commission on Secondary Education.

IT is announced that a school for post-graduate medical study, to be named "The London School of Clinical Medicine," is to be established by the Seamen's Hospital Society at the Dreadnought Seamen's Hospital, Greenwich. The hospital contains 250 beds, and by the addition of eminent members of the medical profession to the present staff, and by an affiliation for teaching purposes with other special hospitals south of the Thames, it is hoped that a complete curriculum for post-graduate study may be arranged. The new school will be complemental to the same society's School of Tropical Medicine at the Albert Dock, which has proved such a success.

AT the session of council of University College, London on November 6, the following resolution was adopted and ordered to be communicated to $\mathrm{Mr}$. Bawden and $\mathrm{Mr}$. Speyer:- "That the most grateful thanks of the council be offered to Mr. E. G. Bawden and Mr. Edgar Speyer for providing and allotting the sum of $16,000 l$ - - to be known as ' the Bawden Fund '-to the fund for advanced university education and research, thereby making up the balance of the sum of $200,000 l$. necessary to complete the financial arrangements for the incorporation of the college in the university. The council are of opinion that by promoting the incorporation of the college in the university they can most effectually realise the purposes for which the college was founded and can best advance the cause of learning and science. They therefore feel that they can congratulate Mr. Bawden and Mr. Speyer on helping to complete an arrangement that is likely to have, a farreaching influence in the furtherance of advanced education and research in London.' 